\title{
地表环境监测现状及优化措施分析
}

\author{
蒋亮刘明野 \\ 沈阳中天星艺环保科技有限公司
}

DOI:10.32629/eep.v3i4.735

[摘 要] 为满足社会经济发展的要求, 能源开采力度不断增加, 地表环境监测作为环境监测的主要内容, 对环境保护、污染治理有非常重要的意 义,也影响着我国的经济发展和人民的日常生产生活。基于此,本文结合理论实践,在简要阐述地表环境监测必要性的基础上,分析了目前地表环 境监测发展现状,并提出相应的优化措施,希望对我国环境监测所有帮助。

[关键词] 地表环境; 环境监测; 监测制度; 监测技术

地表环境监测是我国土地资源和水资源管理的核心内容, 通过对地表 环境中的污染物、污染因素等进行有效监测, 可为评估地表环境污染问题、 治理污染等提供必要的技术支持。目前我国地表污染问题还在不断加重, 监测任务越来越大, 还存在很多问题亟待解决, 严重限制了我国地表环境 监测水平的提升。

\section{1 地表环境监测的必要性}

地表是人类赖以生存的主要资源, 人们生活、生产、工作都离不开 地表环境。一旦地表被污染, 就会影响是人类身心健康, 引发各种疾病。 我国是发展中国家, 还需要工业、农业等来推动我国经济增长, 但工业和 农业污染排放量比较大, 对地表生态环境和人类生活已经构成了严重威 胁。虽然很多城镇都设有污水处理厂, 但受到设备、技术、工艺的影响, 无法根除污水中的污染物, 我国超过 $90 \%$ 的地表水存在污染问题, 对地表 环境造成了严重破坏。通过地表环境监测, 可获知地表环境污染程度、 污染源、污染种类等, 从而为治理地表环境污染问题提供必要的数据支 持和理论指导。

\section{2 地表环境监测现状分析}

2. 1 缺乏完善监测制度

现阶段, 我国地表环境监测, 主要针对的污染因子微生物、无机污染、 重金属污染等, 全面性不足, 无法对地表环境的污染程度进行全面客观的 分析评估, 也就无法找到有针对性的解决措施。监测制度不完善, 就会引发 严重的监测项目缺失问题, 致使一些污染因子没有被监测出来。目前我国 地表环境污染以有机物污染为主, 比如: 在地表水环境监测中, 都通过COD 和BOD来评价水体污染情况, 并不能客观、准确的反映水体污染情况, 是目 前地表环境监测中面临的主要问题。

\section{2 监测技术和监测设备比较滞后}

就我国目前环境监测发展现状而言, 在地表环境监测中, 应用的监测 技术和设备仪器还比较落后, 难以满足日益复杂的地表环境监测要求。比 如: 在地表水环境监测中, 多采用理化结合技术, 监测技术含量还比较低。

2. 3监测资金有限, 缺乏高素质监测人才

虽然近年来, 国家越来越重视环境保护, 但多集中在大气污染质量、水 体污染治理、垃圾处理等方面, 对地表环境监测重视度不足, 投入的资金有 限。致使先进的地表环境监测技术和设备难以大范围推广应用。再加上缺 乏高素质监测人才, 地表环境监测效率还比较低, 监测数据可靠性不足。

\section{3 优化地表环境监测质量的措施}

3. 1 构建完善的地表环境监测制度

可参照国外等发达国家的地表环境监测制度, 结合我国地表环境发展 现状, 科学合理的编制监测制度, 明确地表环境监测的范围、目的、操作规
范、技术标准等。按照现有的地表环境监测质量标准, 按照不同的评价目 的, 制定相应的监测制度, 不能用一个标准衡量所有地表环境监测。比如: 在地表水环境监测时, 可将饮用水源单独罗列出来, 分别评价水体的富氧 化和水体功能, 严格按照监测制度, 开展地表水环境监测, 从而提升监测结 果的可信度和可靠性。

3.2 采样先进的监测技术和设备

地表环境监测时可加大信息技术的应用力度, 对重点区域的土壤、水 体等进行预测评估, 在污染问题发生之前, 就采取相应的解决措施, 降低污 染程度和范围。比如: 在地表环境监测中可采用的信息化技术包括: 时间 序列法、回归分析法、灰色模型、人工神经网络法等。时间序列法在地表 环境监测中, 仅仅考虑指标因素, 但如今地表污染比较复杂, 此种预测方法 的精度比较低; 回归分析法在应用时需要大量数据的支撑, 属于一种静态 分析方法, 局限性比较大; 灰色模式应用时受到时间的影响比较大, 通常情 况下, 时间越长, 预测精度就越低; 人工神经网络可以按照地表环境的特点 自行学习, 自动获取的阈值和权值, 预测方法比较高, 可行度也比较好, 值 得大范围推广应用。

3. 3 加大投资力度, 引入高素质人才

地表环境监测是一项非常复杂的工作, 需要大量资金的支持才能完成, 因此, 环境监测单位必须要让当地政府认识地表环境监测的重要性, 加到 投资力度, 保证各项监测工作能够顺利开展。同时, 加大提高素质人才队伍 建设力度, 通过高薪聘请、人才培养等方式, 不断提升地表环境监测人员的 专业水平和业务水平, 以保证监测数据的可靠性, 为制定地表环境污染治 理方案和措施提供数据支持。

\section{4 结束语}

综上所述, 本文结合理论实践, 分析了地表环境监测现状及优化措施, 分析结果表明地表环境监测是环境监测的主要内容, 在保护环境、污染治 理当方面有重要意义。随着我国社会经济的发展, 地表资源污染问题愈发 严峻, 开展地表环境监测有非常重要的现实意义。针对目前发展现状, 可从 构建制度、引进新技术新设备、加大投资力度、培养高素质人才等方面同 时入手。以推动地表水监测获得新的进展, 实现其效益。

[参考文献]

[1]王国军.环境监测中地表水监测现状及进展分析 [J].环境与发 展,2019,(5):165.

[2]莫子毅.环境检测中地表水监测现状与发展研究 [J].石化技 术,2018,25(06):262.

[3]高鹏园.地表水环境监测现状及优化措施分析 [J]. 化工管 理,2020,(01):121+126. 